OPEN ACCESS

Edited by:

Gavan McNally,

University of New South Wales,

Australia

Reviewed by:

Jessica R. Barson,

Drexel University, United States

Nathan James Marchant,

VU University Medical Center,

Netherlands

*Correspondence:

Chuanzhong Yang

yangczgd@163.com

Yingjie Zhu

yj.zhu1@siat.ac.cn

tThese authors have contributed equally to this work

Specialty section:

This article was submitted to

Motivation and Reward,

a section of the journal

Frontiers in Behavioral Neuroscience

Received: 28 November 2020

Accepted: 11 January 2021

Published: 16 February 2021

Citation:

Zhou K, Zhu L, Hou G, Chen X, Chen B, Yang $C$ and Zhu Y (2021) The Contribution of Thalamic Nuclei in Salience Processing.

Front. Behav. Neurosci. 15:634618. doi: 10.3389/fnbeh.2021.634618

\section{The Contribution of Thalamic Nuclei in Salience Processing}

\author{
Kuikui Zhou ${ }^{1 \dagger}$, Lin Zhu' ${ }^{2 t}$, Guoqiang Hou ${ }^{1 \dagger}$, Xueyu Chen ${ }^{2}$, Bo Chen ${ }^{1}$, Chuanzhong Yang ${ }^{2 *}$ \\ and Yingjie Zhu ${ }^{1 *}$
}

\begin{abstract}
${ }^{1}$ Shenzhen Key Laboratory of Drug Addiction, CAS Key Laboratory of Brain Connectome and Manipulation, The Brain Cognition and Brain Disease Institute (BCBDI), Shenzhen Institutes of Advanced Technology, Chinese Academy of Sciences, Shenzhen-Hong Kong Institute of Brain Science-Shenzhen Fundamental Research Institutions, Shenzhen, China, ${ }^{2}$ Department of Neonatology, Shenzhen Maternity \& Child Healthcare Hospital, The First School of Clinical Medicine, Southern Medical University, Shenzhen, China
\end{abstract}

The brain continuously receives diverse information about the external environment and changes in the homeostatic state. The attribution of salience determines which stimuli capture attention and, therefore, plays an essential role in regulating emotions and guiding behaviors. Although the thalamus is included in the salience network, the neural mechanism of how the thalamus contributes to salience processing remains elusive. In this mini-review, we will focus on recent advances in understanding the specific roles of distinct thalamic nuclei in salience processing. We will summarize the functional connections between thalamus nuclei and other key nodes in the salience network. We will highlight the convergence of neural circuits involved in reward and pain processing, arousal, and attention control in thalamic structures. We will discuss how thalamic activities represent salience information in associative learning and how thalamic neurons modulate adaptive behaviors. Lastly, we will review recent studies which investigate the contribution of thalamic dysfunction to aberrant salience processing in neuropsychiatric disorders, such as drug addiction, posttraumatic stress disorder (PTSD), and schizophrenia. Based on emerging evidence from both human and rodent research, we propose that the thalamus, different from previous studies that as an information relay, has a broader role in coordinating the cognitive process and regulating emotions.

Keywords: salience, motivated behaviors, thalamus, paraventricular thalamus, mediodorsal thalamus

\section{INTRODUCTION}

Complex sensory inputs about the external world and constant update of the internal state are fed into our neural system at every moment. The ability to capture the most relevant information from the noisy background is critical to both learning and survival. The saliency of a stimulus is not only determined by its physical properties but also influenced by different behavioral context and motivational states (Puglisi-Allegra and Ventura, 2012). Therefore, salience processing requires the cooperation of sensory, emotion, and attention systems throughout the brain (Uddin, 2015; Peters et al., 2016).

A variety of neuroimaging studies have revealed the cortical nodes of the salience network, the dorsal anterior cingulate cortex (dACC), and anterior insula (AI) (Downar et al., 2000, 2001; 
Seeley et al., 2007). Subcortical structures including the thalamus, the striatum, and the midbrain dopamine nuclei, which cooperate with the cortical nodes in cognitive control, also contribute to salience processing (Menon, 2011; Yeo et al., 2011; Wolff and Vann, 2019). Thalamic nuclei have reciprocal connections with the cerebral cortex and subcortical structures, participating in the regulation of arousal, emotion, and cognitive attention control (Schmahmann, 2003; Wolff and Vann, 2019). In the current mini-review, we will discuss the potential mechanism how the thalamus contributes to salience processing. Functional connectivity profiles of thalamic nuclei could throw light on how the thalamus might coordinate cortical and subcortical activities. Recordings of thalamic activities during adaptive behaviors provide critical evidence on how thalamic neurons encode salience and hence contribute to associative learning. We will also review recent evidence showing that dysfunction of thalamic nuclei is implicated in neural pathologies.

\section{CONNECTIVITY PROFILES OF THALAMIC NUCLEI}

Early ideas about thalamic anatomy and function were derived from classic studies of the LGN (lateral genicular nucleus) (Hubel and Wiesel, 1962). LGN neurons receive topographic input from the retina and exhibit highly topographic projections and specific laminar patterns of terminations in the primary visual cortex. Therefore, it was widely believed that the thalamus is responsible for precise "bottom-up" transmission of input to primary cortical targets. In fact, this traditional view merely represents the anatomy and function of a restricted group of thalamic nuclei; other thalamic nuclei show distinct projection patterns, which are also categorized as non-specific thalamic nuclei (Kamikawa et al., 1967; Van der Werf et al., 2002; Vertes et al., 2015). For example, axon collaterals of neurons in the paraventricular thalamus (PVT) extend to the prefrontal cortex (PFC), nucleus accumbens (NAc), bed nucleus of the stria terminalis (BNST), and central amygdala (CeA), allowing simultaneous activation of distant brain regions (Bubser and Deutch, 1998; Dong et al., 2017; Millan et al., 2017). Non-specific thalamic nuclei, such as the midline and intralaminar thalamus, which do not receive direct input from ascending tracts but have diffuse projections to limbic cortical areas, hypothalamus and striatum (Kuramoto et al., 2015, 2017), will be the main focus of the current review.

Thalamocortical projections exhibit interesting anatomical features, which support the role of the thalamus in orchestrating cortical activities and regulating cognitive functions. For example, single neurons in the mediodorsal thalamus (MD) send axons to multiple prefrontal areas and form patchy axon arbors. This organization allows MD neurons to recruit a specific set of cortical neurons in distant cortical regions, compatible with the role of the MD in coordinating task-relevant cortical representations. In addition, thalamic axon arborizations are found not only in the relay layer (layer4) but also in the superficial layers of the cerebrocortex (Avendano et al., 1990; Rubio-Garrido et al., 2009), which are essential for information transmission and cortical computation. Another key feature of the thalamocortical pathway is the robust feedforward inhibition mediated by cortical inhibitory neurons (Cruikshank et al., 2007, 2010; Bagnall et al., 2011). A recent study reported that two thalamic nuclei target distinct types of cortical interneurons in the PFC and thus have differential influence on dendritic and somatic activity (Anastasiades et al., 2020). These properties are well equipped for temporal precise and pathway-specific regulation of cortical output. Besides reciprocal connections with the cerebral cortex, the thalamus receives extensive input from the brainstem and hypothalamus, obtaining information about general arousal and interoceptive states (Sherman, 2007; Kumar et al., 2017). The thalamus also projects to the striatum and amygdala, supporting its role in orientating motivation and regulating emotion.

Altogether, the thalamus is in position to detect and orientate neural resources toward behavioral relevant stimuli. This view is further evidenced by myriad functional imaging studies (Robinson and Petersen, 1992; Peters et al., 2016). On top of that, emerging circuitry studies investigating thalamic control of awareness and cognitive process have brought to light the mechanism how the thalamus contributes to salience control (Floresco and Grace, 2003; Halassa et al., 2014; Rikhye et al., 2018). In the subsequent sections, we will highlight recent advances in understanding the role of thalamic pathways in arousal and attention control, pain and reward, and emotion regulation.

\section{Thalamic Pathways Regulating Arousal State}

Salience processing is often associated with amplification of certain sensory inputs and enhanced functional connectivity, whereas arousal also requires enhanced brain excitability and connectivity, but at a more general scale (Massimini et al., 2005; Nakajima and Halassa, 2017). Therefore, salience attribution could be conceptualized as dynamic control of specific arousal states of task-related neural circuits (Sakai, 2008). We will review evidence that thalamic circuitry participates in arousal regulation, aiming to give some clues on how the thalamus might contribute to salience processing.

Midline thalamic nuclei receiving hypothalamic and brainstem inputs connect with widespread cortical areas (Herkenham, 1979; Kuramoto et al., 2015). Hence, midline thalamic nuclei are well positioned anatomically to summate subcortical arousal information and modulate forebrain activity strongly and diffusely (Matyas et al., 2018; Ren et al., 2018). The PVT receives input from the brainstem arousal nuclei, such as the locus coeruleus and reticular formation (Krout et al., 2002; Li and Kirouac, 2012). Moreover, it is reciprocally connected with the suprachiasmatic nucleus (Alamilla et al., 2015; Yuan et al., 2018), which is the primary circadian pacemaker in the brain. Moreover, the PVT is also densely innervated by orexinergic fibers (Matzeu et al., 2014), the activation of which depolarizes postsynaptic PVT neurons (Ishibashi et al., 2005). Compelling evidence has demonstrated a key role of the orexin/hypocretin system in arousal and maintenance of the awaking state (de Lecea, 2012). Activation of the PVT effectively promotes wakefulness under the regulation of hypocretin neurons in the 
lateral hypothalamus (Ren et al., 2018). Moreover, different PVT output pathways might be in charge of arousal regulation in various homeostatic states (Hua et al., 2018; Meffre et al., 2019). However, a recent study found a subpopulation of PVT neurons that are negatively modulated by wakefulness and arousal (Gao et al., 2020). This discrepancy might rise from the difference in anatomical location that previous studies focused on the posterior part of the PVT, whereas the recent one investigated a genetically defined subgroup of neurons which populates in the anterior part. Future studies examining the afferents of distinct PVT subregions and subpopulations will help clarify the role of the PVT in arousal.

The majority of thalamic neurons are glutamatergic; however, neurons in the reticular thalamus (TRN) are primarily GABAergic and exert inhibitory control over thalamic nuclei (Halassa and Acsady, 2016). Spontaneous firing of midline thalamic neurons in mice is phase-advanced to global cortical up states (Gent et al., 2018). Whereas enhanced spiking during sleep is found in TRN subnetworks that project to sensory-related thalamic circuits (Halassa et al., 2014; Chen et al., 2015b), attention decreases TRN responses to visual stimuli (McAlonan et al., 2008). The TRN regulates thalamocortical activities and has a causal role in generating sleep spindles (Bazhenov et al., 2000; Cueni et al., 2008; Halassa et al., 2011). Optogenetic manipulations of TRN activities bidirectionally modulate arousal states (Lewis et al., 2015; Herrera et al., 2016). Recent studies have revealed that cholinergic and noradrenergic inputs to the TRN participate in regulating sleep and arousal (Ni et al., 2016; Zhang et al., 2019).

\section{Pain- and Reward-Related Thalamic Pathways}

Neurocircuits regulating pain and reward have been considered as part of the system orientating attention toward various salient stimuli (Roland, 1992; Uddin, 2015; Kummer et al., 2020). Thalamic neurons receiving inputs from the spinal cord, the midbrain, and the hypothalamus (Yen and Lu, 2013; Kirouac, 2015) are activated by noxious and appetitive stimuli (Casey and Morrow, 1983; Kim et al., 2003). The medial and intralaminar thalamic nuclei are the major source of painassociated information to the limbic cortex (Livneh et al., 2017; Meda et al., 2019; Liang et al., 2020a).

Inactivation of the dorsal thalamic nuclei has been shown to suppress pain and pain related aversion (Jurik et al., 2015; Cheng et al., 2017; Zhou et al., 2019). In addition, the ratio between excitation and feedforward inhibition of thalamic input to the cortex is important for the regulation of affective pain (Jurik et al., 2015; Meda et al., 2019). Activation of the PVTCeA pathway induces mechanical allodynia (Liang et al., 2020b), reflecting a potential role of the PVT in pain-associated salience attribution. The PVT is also engaged in reward-seeking behaviors (James et al., 2011a; Browning et al., 2014; Choudhary et al., 2018). The PVT shows increased neuronal activation in response to reward and reward-associated cues (Igelstrom et al., 2010; James et al., 2011a; Yeoh et al., 2014; Munkhzaya et al., 2020). Suppression of PVT activities could attenuate reward-motivated behaviors (Hamlin et al., 2009; Ong et al., 2017) (but see Stratford and Wirtshafter, 2013; Zhang and van den Pol, 2017). A growing body of evidence suggests that the PVT plays a role in integrating complex homeostatic signals and informing adaptive behaviors during motivational conflicts (Ferrario et al., 2016; Choi and McNally, 2017; Meffre et al., 2019). Using in vivo singleunit recording, Zhu et al. showed that posterior PVT neurons could be activated by both rewarding and aversive stimulus and the cues predicting those outcomes, indicating that the pPVT encodes stimulus salience irrespective of valance (Zhu et al., 2018). By alterations of the behavioral context and modulation of homeostatic states, they further demonstrated that the PVT provides dynamic representation of salience and thus contribute to associative learning.

\section{Thalamic Circuitry in the Regulation of Attention}

By definition, salience describes the ability of a stimulus or an event to capture attention. On the other hand, salience attribution is strongly influenced by top-down attention control and emotional states. Thalamic nuclei, such as the anterior thalamic nuclei (ATN) and the MD, contribute to attention control primarily via their connections with limbic structures (Parnaudeau et al., 2013; Wright et al., 2015; Wolff and Vann, 2019). The ATN is densely connected with both the hippocampus and the frontal lobe and thus is believed to play a role in memoryguided attention (Leszczynski and Staudigl, 2016). Using deep brain stimulation (DBS) in human subjects, studies suggest that the ATN is involved in emotion-attention interaction (Hartikainen et al., 2014; Sun et al., 2015).

Accumulating evidence from human and animal studies have indicated that disruption of the MD impairs cognitive processes (Block et al., 2007; Nakajima and Halassa, 2017; Parnaudeau et al., 2018; Pergola et al., 2018). Anatomically, the MD receives modulatory input from the midbrain and brainstem and forms a reciprocal connection with the frontal cortex (Russchen et al., 1987; Mitchell, 2015; Collins et al., 2018). Single MD neurons receive convergence of small cortical inputs and project to multiple cortices across multiple layers (Rubio-Garrido et al., 2009; Kuramoto et al., 2017; Georgescu et al., 2020). Schmitt et al. (2017) proposed that the MD sustains rule representations in the PFC. Interestingly, enhancing MD excitability improved rule specificity and behavioral performance, in contrast to the reduction of rule information induced by enhancing PFC excitability. These results imply that the MD input exerts the effect by regulating the functional micro-circuitry in the PFC instead of non-selectively boosting the excitability of pyramidal neurons.

Dynamic control of salience is also reflected in the process of cognitive switching, which is important for action selection and behavioral flexibility. Thalamic nuclei are involved in cognitive switching primarily through connections with the striatum and PFC (Phillips et al., 2016). The centromedian (CM) and parafascicular nucleus $(\mathrm{PF})$ are the major thalamic input to the dorsal striatum (DS) (Ilyas et al., 2019). Primate studies have suggested that the CM and PF provide the striatum with 
information about salience (Matsumoto et al., 2001; Minamimoto and Kimura, 2002; Yamanaka et al., 2018). Studies in rodents extend these findings by showing that disruption of CM/PF-DS pathway increased the perseverative responses and aggravated the interference between new and old learning (Bradfield et al., 2013; Bradfield and Balleine, 2017; Saund et al., 2017; Kato et al., 2018). The MD also contributes to behavioral flexibility and probably exerts its role through feedforward inhibition (Kuroda et al., 2004; Rotaru et al., 2005; Block et al., 2007; Delevich et al., 2015). In addition, a recent study suggested that MD-mediated suppression preserves unused cortical traces for future use (Rikhye et al., 2018). Subnetworks in the TRN exert inhibitory control over spatially discrete thalamic targets, suppressing distracting inputs (Pinault and Deschenes, 1998; Zikopoulos and Barbas, 2012; Halassa et al., 2014; Wimmer et al., 2015). Although the PFC does not directly project to the TRN, the PFC could regulate modality specific TRN subnetworks via the globus pallidus (GP) (Nakajima et al., 2019). In addition, the TRN is innervated by amygdalar input, providing a mechanism for emotion-driven attention shift (Zikopoulos and Barbas, 2012).

\section{Thalamic Circuitry in the Regulation of Emotion}

Without adequate assignment of salience, stimuli that typically trigger mood and emotions can no longer attract one's interest to act and react. Thus, it is not surprising that aberrant functional connectivity in the salience network is frequently observed in depressed patients (Pannekoek et al., 2014; Yuen et al., 2014; Rzepa and McCabe, 2016). Functional MRI studies have reported decreased functional connectivity between the dACC and the MD in the depressed patients (Wang et al., 2012). Moreover, improved MD-PFC connectivity has been associated with effective depression treatments (Salomons et al., 2014; Leaver et al., 2016). Consistently, synaptic strength of the MDPFC pathway is reduced in a rodent model of depression, while activation of this pathway is sufficient to reduce depressionlike behavior (Miller et al., 2017). Interestingly, a recent study found that the visual thalamus could affect the midbrain monoaminergic centers via the lateral habenula (Huang et al., 2019). In addition, this pathway might mediate the antidepressive effect of light therapy.

Thalamic nuclei modulate both innate fear and conditioned fear responses (Li et al., 2004; Penzo et al., 2015; Salay et al., 2018). Fear extinction is a process involving progressive suppression of the salience of fear-associative cue or context. Manipulations of thalamic activities have been shown to bidirectionally modulate fear extinction (Padilla-Coreano et al., 2012; Matyas et al., 2014; Paydar et al., 2014; Do-Monte et al., 2015; Lee et al., 2019; Ramanathan and Maren, 2019). Thalamic neurons exhibit two firing modes, tonic and burst, which could modulate behaviors in opposite directions (Sherman, 2001). Using tetrode recording in free-moving mice, Lee et al. (2011) showed that the tonic firing frequency of MD neurons positively correlates with the extent of fear extinction. In addition, enhancing tonic firing of MD neurons facilitated fear extinction, whereas burst-evoking stimulation suppressed extinction, indicating that distinct firing modes of MD neurons might bidirectionally modulate salience of fear-associated cue (Lee et al., 2011; Georgescu et al., 2020).

On the other hand, augmented observational fear responses have been demonstrated in socially related conspecifics (Jeon et al., 2010). Social transmission of fear is associated with a significant increase of activity in the PVT, MD, and ACC (Chang and Debiec, 2016; Zheng et al., 2020). Since the PVT and MD have been reported to regulate social related behaviors (Zhou et al., 2017; Watarai et al., 2020; Yamamuro et al., 2020), they might participate in social salience modulation of fear response.

\section{THALAMIC DYSFUNCTION AND NEUROPSYCHIATRIC DISORDERS}

Given the essential role of the thalamus in salience processing, it is perhaps not surprising that altered connectivity patterns and responses of thalamic nuclei have been poised to contribute to the aberrant salience attribution in neuropsychiatric disorders. Below, we will describe the engagement of thalamic dysfunction in three distinct mental disorders, in which dysregulation of salience processing is often observed.

\section{Drug Addiction Disorder}

Drugs of abuse profoundly modulate neural response toward previous neutral stimuli which become associated with drugs. The development of incentive salience of drug-paired context or cues is an essential component of drug addiction (Koob and Volkow, 2016). As discussed above, the PVT is anatomically well positioned to coordinate drug-related behaviors (Browning et al., 2014; Zhou and Zhu, 2019). PVT neurons express orexin, opioid, and dopaminergic receptors and receive multiple neuromodulatory inputs (Mansour et al., 1986; Clark et al., 2017). PVT neuronal activity and plasticity in PVT-related pathways are modulated by drug-related behaviors (Deutch et al., 1998; Kolaj et al., 2014; Yeoh et al., 2014; Chen et al., 2015a; Zhu et al., 2016). Consistent with the idea that PVT neurons encode stimulus salience, a recent study showed that manipulations of the PVT-CeA pathway could bidirectionally modulate morphine-conditioned place preference, suggesting that the PVT-CeA pathway associates incentive salience of the drug with paired environment (Keyes et al., 2020). However, manipulations of the PVT pathways could result in diverse outcomes in literature (Table 1). Further investigation of the heterogeneity in anatomical location, connectivity profile, activity pattern, and genetic markers of the PVT neurons might help to resolve this ambiguity (Millan et al., 2017; McGinty and Otis, 2020).

The phenomenon that drug-seeking behaviors progressively increase after abstinence is termed incubation of craving (Lu et al., 2004; Pickens et al., 2011). In addition to the contribution of the mesolimbic dopaminergic signal (Caprioli et al., 2017; Rossi et al., 2020), glutamate has been shown to participate in incubation of craving (Li et al., 2015; Shin et al., 2016). 
TABLE 1 | Effect of PVT manipulations on drug related behaviors.

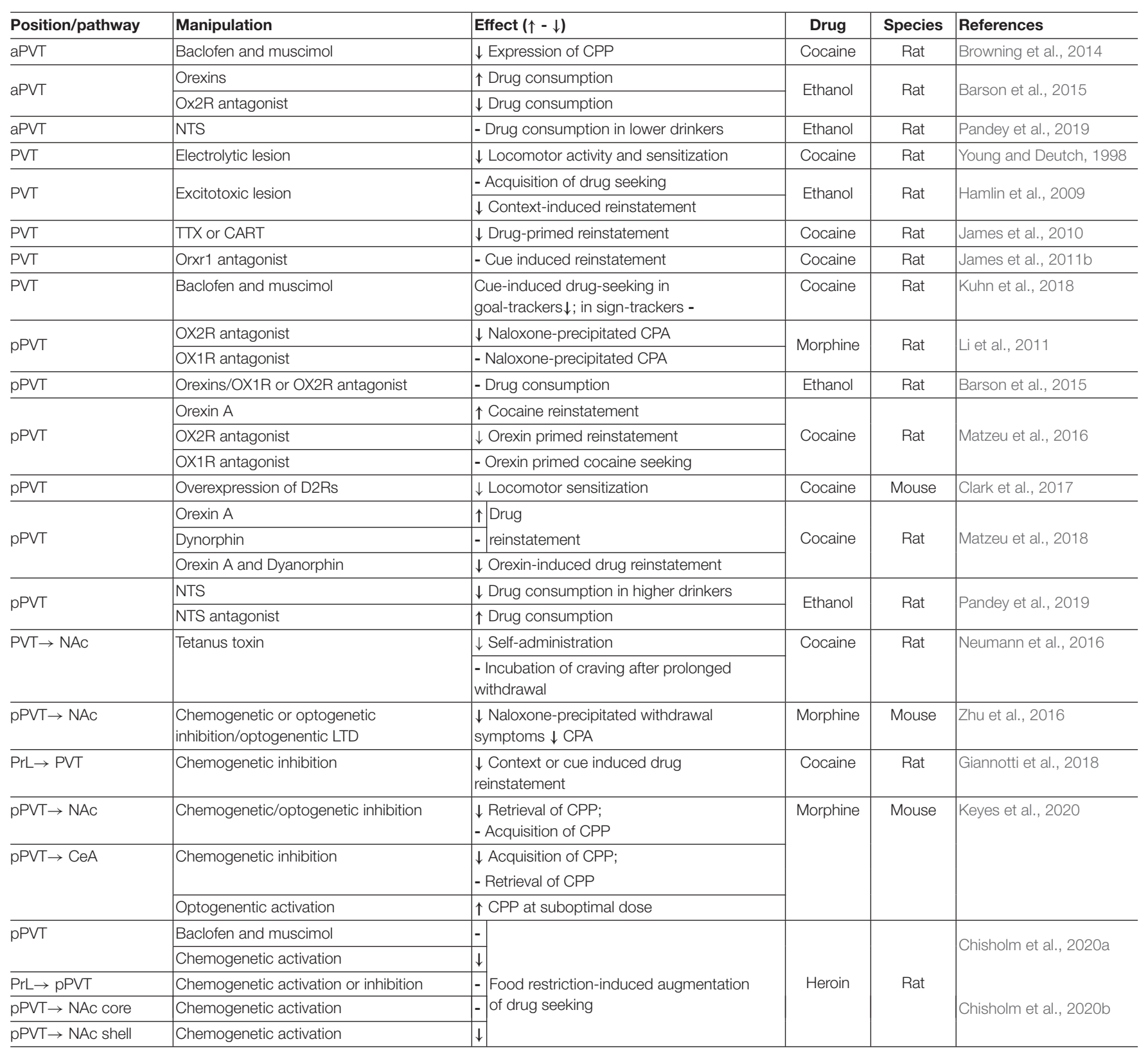

Incubated methamphetamine (Meth) seeking selectively activated glutamatergic input from anterior intralaminar nuclei of the thalamus (AIT) to dorsomedial striatum (DMS) (Li et al., 2018). Furthermore, inactivation of the AIT-DMS pathway attenuated incubated Meth craving while leaving non-incubated Meth seeking intact. These results suggest a critical role of the AIT in the regulation of incentive salience and drug relapse.

\section{Posttraumatic Stress Disorder}

Posttraumatic stress disorder (PTSD) is a long-lasting and recurring mental disorder triggered by traumatic experience. Trauma recollection is associated with enhanced connectivity in the salience network, while salience connectivity is reduced following effective treatment in PTSD patients (Abdallah et al., 2019a,b). PTSD subjects showed significantly less activation of the thalamus (Lanius et al., 2001; SuarezJimenez et al., 2020). In a case report, new onset of PTSD occurred after thalamic infarct in a Korean War veteran (Duggal, 2002). In addition, an fMRI study showed that a larger magnitude of spontaneous activity in the thalamus is associated with lower reexperiencing symptoms in PTSD (Yan et al., 2013). Studies in rodent animals further analyzed the requirement of thalamic function during different time points of fear retrieval. For example, the PVT is gradually recruited during fear retrieval (Padilla-Coreano et al., 2012). 
Suppression of the PVT-CeA pathway disrupts fear retrieval at late but not early time points, suggesting the induction of long-term plasticity in this pathway (Do-Monte et al., 2015; Penzo et al., 2015).

Psychotherapeutic strategies for treating PTSD often involve reassignment of salience and modulation of attentional processes (Badura-Brack et al., 2015). For example, eye movement desensitization and reprocessing (EMDR) is a treatment using alternating bilateral sensory stimulation (ABS) to interfere with fear memory recall (Novo Navarro et al., 2018). The mechanism underlying the therapeutic effect of visual ABS can be inferred from the study by Baek et al. They found that ABS could drive activity in the superior colliculus (SC)-MD pathway which induces sustained BLA inhibition during fear extinction (Baek et al., 2019). Their results argue that MD mediates the competition between visual-attentional process and emotional activity and serves as a key target of treatment for PTSD.

\section{Schizophrenia}

Schizophrenia is a mental disorder involving a range of problems in cognition, emotion, and behaviors. One influential theory about schizophrenia is that positive symptoms including hallucination and illusion could be attributed to aberrant assignment of salience to a certain experience or internal representation (Kapur, 2003; van Os and Kapur, 2009; Kim et al., 2018).

Abnormalities in structure and function of the thalamus have been associated with schizophrenia (Byne et al., 2009). According to genome-wide association studies, thalamic neurons express several schizophrenia-relevant genes (Watis et al., 2008; Pergola et al., 2015; Takahashi et al., 2015; Krol et al., 2018). A reduced volume of the thalamus has been found in schizophrenia patients (Volz et al., 2000; Konick and Friedman, 2001). A decreased number of parvalbumin (PV) neurons in the thalamus have been reported in human postmortem schizophrenia brains and rodent models (Danos et al., 1998; Steullet et al., 2018). Studies indicate that thalamocortical connections are compromised in schizophrenia (Sharp et al., 2001; Woodward et al., 2012; Avram

\section{REFERENCES}

Abdallah, C. G., Averill, C. L., Ramage, A. E., Averill, L. A., Alkin, E., Nemati, S., et al. (2019a). Reduced salience and enhanced central executive connectivity following PTSD treatment. Chronic Stress (Thousand Oaks) 3:2470547019838971. doi: 10.1177/2470547019838971

Abdallah, C. G., Averill, C. L., Ramage, A. E., Averill, L. A., Goktas, S., Nemati, S., et al. (2019b). Salience network disruption in U.S. Army soldiers with posttraumatic stress disorder. Chronic Stress (Thousand Oaks) 3:2470547019850467. doi: 10.1177/2470547019850467

Alamilla, J., Granados-Fuentes, D., and Aguilar-Roblero, R. (2015). The anterior paraventricular thalamus modulates neuronal excitability in the suprachiasmatic nuclei of the rat. Eur. J. Neurosci. 42, 2833-2842. doi: 10.1111/ ejn. 13088

Anastasiades, P. G., Collins, D. P., and Carter, A. G. (2020). Mediodorsal and ventromedial thalamus engage distinct L1 circuits in the prefrontal cortex. Neuron 109, 314-330.e4. doi: 10.1016/j.neuron.2020.10.031

Anticevic, A., Cole, M. W., Repovs, G., Murray, J. D., Brumbaugh, M. S., Winkler, A. M., et al. (2014). Characterizing thalamo-cortical disturbances in et al., 2018; Delevich et al., 2020), which might cause disturbances in sensory gating and top-down control (Anticevic et al., 2014).

\section{FUTURE DIRECTIONS}

As discussed above, thalamic neurons could encode salient features of stimuli, contributing to cognitive process and emotional regulation. However, it remains unknown how the information of salience is integrated from distinct pathways in single thalamic neurons. Also, it is worth further investigating the role of the neuromodulatory system on salience control in the thalamus. Stress induces perturbations in the structure and function of the brain, which present a major risk factor for many neuropsychiatric disorders. Future studies describing the molecular and circuitry adaptations in acute and chronic stress, would help us to analyze the contribution of the thalamus to salience allocation under pathological conditions.

\section{AUTHOR CONTRIBUTIONS}

$\mathrm{KZ}$, LZ, and GH contributed equally to the writing of this review article. All authors contributed to the article and approved the submitted version.

\section{FUNDING}

This work was supported by the Shenzhen Governmental grants JCYJ20180507182420114, JCYJ20180302145554969, JCYJ20170818163217196, and JCYJ20170818162613877, the Sanming Project of Medicine in Shenzhen (SZSM201612045), the Shenzhen Fund for Guangdong Provincial High-level Clinical Key Specialties (No. SZGSP009), the National Natural Science Foundation of China (Grant Nos. 31900735, 31900809, and 81922024), and the Frontier Research Program of Bioland Laboratory (Guangzhou Regenerative Medicine and Health Guangdong Laboratory) (2018GZR110105006).

schizophrenia and bipolar illness. Cereb. Cortex 24, 3116-3130. doi: 10.1093/ cercor/bht165

Avendano, C., Stepniewska, I., Rausell, E., and Reinoso-Suarez, F. (1990). Segregation and heterogeneity of thalamic cell populations projecting to superficial layers of posterior parietal cortex: a retrograde tracer study in cat and monkey. Neuroscience 39, 547-559. doi: 10.1016/0306-4522(90) 90242-v

Avram, M., Brandl, F., Bauml, J., and Sorg, C. (2018). Cortico-thalamic hypoand hyperconnectivity extend consistently to basal ganglia in schizophrenia. Neuropsychopharmacology 43, 2239-2248. doi: 10.1038/s41386-018-0059-z

Badura-Brack, A. S., Naim, R., Ryan, T. J., Levy, O., Abend, R., Khanna, M. M., et al. (2015). Effect of attention training on attention bias variability and PTSD symptoms: randomized controlled trials in Israeli and U.S. combat veterans. Am. J. Psychiatry 172, 1233-1241. doi: 10.1176/appi.ajp.2015.14121578

Baek, J., Lee, S., Cho, T., Kim, S. W., Kim, M., Yoon, Y., et al. (2019). Neural circuits underlying a psychotherapeutic regimen for fear disorders. Nature 566, 339-343. doi: 10.1038/s41586-019-0931-y

Bagnall, M. W., Hull, C., Bushong, E. A., Ellisman, M. H., and Scanziani, M. (2011). Multiple clusters of release sites formed by individual thalamic afferents 
onto cortical interneurons ensure reliable transmission. Neuron 71, 180-194. doi: 10.1016/j.neuron.2011.05.032

Barson, J. R., Ho, H. T., and Leibowitz, S. F. (2015). Anterior thalamic paraventricular nucleus is involved in intermittent access ethanol drinking: role of orexin receptor 2. Addict. Biol. 20, 469-481. doi: 10.1111/adb.12139

Bazhenov, M., Timofeev, I., Steriade, M., and Sejnowski, T. (2000). Spikingbursting activity in the thalamic reticular nucleus initiates sequences of spindle oscillations in thalamic networks. J. Neurophysiol. 84, 1076-1087. doi: 10.1152/ jn.2000.84.2.1076

Block, A. E., Dhanji, H., Thompson-Tardif, S. F., and Floresco, S. B. (2007). Thalamic-prefrontal cortical-ventral striatal circuitry mediates dissociable components of strategy set shifting. Cereb. Cortex 17, 1625-1636. doi: 10.1093/ cercor/bhl073

Bradfield, L. A., and Balleine, B. W. (2017). Thalamic control of dorsomedial striatum regulates internal state to guide goal-directed action selection. J. Neurosci. 37, 3721-3733. doi: 10.1523/JNEUROSCI.3860-16.2017

Bradfield, L. A., Bertran-Gonzalez, J., Chieng, B., and Balleine, B. W. (2013). The thalamostriatal pathway and cholinergic control of goal-directed action: interlacing new with existing learning in the striatum. Neuron 79, 153-166. doi: 10.1016/j.neuron.2013.04.039

Browning, J. R., Jansen, H. T., and Sorg, B. A. (2014). Inactivation of the paraventricular thalamus abolishes the expression of cocaine conditioned place preference in rats. Drug Alcohol Depend 134, 387-390. doi: 10.1016/j. drugalcdep.2013.09.021

Bubser, M., and Deutch, A. Y. (1998). Thalamic paraventricular nucleus neurons collateralize to innervate the prefrontal cortex and nucleus accumbens. Brain Res. 787, 304-310. doi: 10.1016/s0006-8993(97)01373-5

Byne, W., Hazlett, E. A., Buchsbaum, M. S., and Kemether, E. (2009). The thalamus and schizophrenia: current status of research. Acta Neuropathol. 117, 347-368. doi: 10.1007/s00401-008-0404-0

Caprioli, D., Venniro, M., Zhang, M., Bossert, J. M., Warren, B. L., Hope, B. T., et al. (2017). Role of dorsomedial striatum neuronal ensembles in incubation of methamphetamine craving after voluntary abstinence. J. Neurosci. 37, 10141027. doi: 10.1523/JNEUROSCI.3091-16.2016

Casey, K. L., and Morrow, T. J. (1983). Ventral posterior thalamic neurons differentially responsive to noxious stimulation of the awake monkey. Science 221, 675-677. doi: 10.1126/science.6867738

Chang, D. J., and Debiec, J. (2016). Neural correlates of the mother-to-infant social transmission of fear. J. Neurosci. Res. 94, 526-534. doi: 10.1002/jnr.2 3739

Chen, Z., Tang, Y., Tao, H., Li, C., Zhang, X., and Liu, Y. (2015a). Dynorphin activation of kappa opioid receptor reduces neuronal excitability in the paraventricular nucleus of mouse thalamus. Neuropharmacology 97, 259-269. doi: 10.1016/j.neuropharm.2015.05.030

Chen, Z., Wimmer, R. D., Wilson, M. A., and Halassa, M. M. (2015b). Thalamic circuit mechanisms link sensory processing in sleep and attention. Front. Neural. Circuits 9:83. doi: 10.3389/fncir.2015.00083

Cheng, Y. F., Chang, Y. T., Chen, W. H., Shih, H. C., Chen, Y. H., Shyu, B. C., et al. (2017). Cardioprotection induced in a mouse model of neuropathic pain via anterior nucleus of paraventricular thalamus. Nat. Commun. 8:826. doi: 10.1038/s41467-017-00891-z

Chisholm, A., Iannuzzi, J., Rizzo, D., Gonzalez, N., Fortin, E., Bumbu, A., et al. (2020a). The role of the paraventricular nucleus of the thalamus in the augmentation of heroin seeking induced by chronic food restriction. Addict. Biol. 25:e12708. doi: 10.1111/adb.12708

Chisholm, A., Rizzo, D., Fortin, E., Moman, V., Quietshat, N., Romano, A., et al. (2020b). Assessing the role of cortico-thalamic and thalamo-accumbens projections in the augmentation of heroin seeking in chronically foodrestricted rats. J. Neurosci. 41, 354-365. doi: 10.1523/JNEUROSCI.2103-20. 2020

Choi, E. A., and McNally, G. P. (2017). Paraventricular thalamus balances danger and reward. J. Neurosci. 37, 3018-3029. doi: 10.1523/JNEUROSCI.3320-16. 2017

Choudhary, A. G., Somalwar, A. R., Sagarkar, S., Rale, A., Sakharkar, A., Subhedar, N. K., et al. (2018). CART neurons in the lateral hypothalamus communicate with the nucleus accumbens shell via glutamatergic neurons in paraventricular thalamic nucleus to modulate reward behavior. Brain Struct. Funct. 223, 1313 1328. doi: 10.1007/s00429-017-1544-6
Clark, A. M., Leroy, F., Martyniuk, K. M., Feng, W., McManus, E., Bailey, M. R., et al. (2017). Dopamine D2 receptors in the paraventricular thalamus attenuate cocaine locomotor sensitization. eNeuro 4: ENEURO.0227-17.2017. doi: 10. 1523/ENEURO.0227-17.2017

Collins, D. P., Anastasiades, P. G., Marlin, J. J., and Carter, A. G. (2018). Reciprocal circuits linking the prefrontal cortex with dorsal and ventral thalamic nuclei. Neuron 98, 366-379 e364. doi: 10.1016/j.neuron.2018.03.024

Cruikshank, S. J., Lewis, T. J., and Connors, B. W. (2007). Synaptic basis for intense thalamocortical activation of feedforward inhibitory cells in neocortex. Nat. Neurosci. 10, 462-468. doi: 10.1038/nn1861

Cruikshank, S. J., Urabe, H., Nurmikko, A. V., and Connors, B. W. (2010). Pathway-specific feedforward circuits between thalamus and neocortex revealed by selective optical stimulation of axons. Neuron 65, 230-245. doi: 10.1016/j.neuron.2009.12.025

Cueni, L., Canepari, M., Lujan, R., Emmenegger, Y., Watanabe, M., Bond, C. T., et al. (2008). T-type Ca2+ channels, SK2 channels and SERCAs gate sleeprelated oscillations in thalamic dendrites. Nat. Neurosci. 11, 683-692. doi: 10. $1038 / \mathrm{nn} .2124$

Danos, P., Baumann, B., Bernstein, H. G., Franz, M., Stauch, R., Northoff, G., et al. (1998). Schizophrenia and anteroventral thalamic nucleus: selective decrease of parvalbumin-immunoreactive thalamocortical projection neurons. Psychiatry Res. 82, 1-10. doi: 10.1016/s0925-4927(97)00071-1

de Lecea, L. (2012). Hypocretins and the neurobiology of sleep-wake mechanisms. Prog. Brain Res. 198, 15-24. doi: 10.1016/B978-0-444-59489-1.00003-3

Delevich, K., Jaaro-Peled, H., Penzo, M., Sawa, A., and Li, B. (2020). Parvalbumin interneuron dysfunction in a thalamo-prefrontal cortical circuit in discl locus impairment mice. eNeuro 7: ENEURO.0496-19.2020. doi: 10.1523/ENEURO. 0496- 19.2020

Delevich, K., Tucciarone, J., Huang, Z. J., and Li, B. (2015). The mediodorsal thalamus drives feedforward inhibition in the anterior cingulate cortex via parvalbumin interneurons. J. Neurosci. 35, 5743-5753. doi: 10.1523/ JNEUROSCI.4565-14.2015

Deutch, A. Y., Bubser, M., and Young, C. D. (1998). Psychostimulant-induced Fos protein expression in the thalamic paraventricular nucleus. J. Neurosci. 18, 10680-10687. doi: 10.1523/jneurosci.18-24-10680.1998

Do-Monte, F. H., Quinones-Laracuente, K., and Quirk, G. J. (2015). A temporal shift in the circuits mediating retrieval of fear memory. Nature 519, 460-463. doi: $10.1038 /$ nature 14030

Dong, X., Li, S., and Kirouac, G. J. (2017). Collateralization of projections from the paraventricular nucleus of the thalamus to the nucleus accumbens, bed nucleus of the stria terminalis, and central nucleus of the amygdala. Brain Struct. Funct. 222, 3927-3943. doi: 10.1007/s00429-017-1445-8

Downar, J., Crawley, A. P., Mikulis, D. J., and Davis, K. D. (2000). A multimodal cortical network for the detection of changes in the sensory environment. Nat. Neurosci. 3, 277-283. doi: 10.1038/72991

Downar, J., Crawley, A. P., Mikulis, D. J., and Davis, K. D. (2001). The effect of task relevance on the cortical response to changes in visual and auditory stimuli: an event-related fMRI study. Neuroimage 14, 1256-1267. doi: 10.1006/nimg.2001. 0946

Duggal, H. S. (2002). New-onset PTSD after thalamic infarct. Am. J. Psychiatry 159, 2113-2114. doi: 10.1176/appi.ajp.159.12.2113-a

Ferrario, C. R., Labouebe, G., Liu, S., Nieh, E. H., Routh, V. H., Xu, S., et al. (2016). Homeostasis meets motivation in the battle to control food intake. J. Neurosci. 36, 11469-11481. doi: 10.1523/JNEUROSCI.2338-16.2016

Floresco, S. B., and Grace, A. A. (2003). Gating of hippocampal-evoked activity in prefrontal cortical neurons by inputs from the mediodorsal thalamus and ventral tegmental area. J. Neurosci. 23, 3930-3943. doi: 10.1523/jneurosci.2309-03930.2003

Gao, C., Leng, Y., Ma, J., Rooke, V., Rodriguez-Gonzalez, S., Ramakrishnan, C., et al. (2020). Two genetically, anatomically and functionally distinct cell types segregate across anteroposterior axis of paraventricular thalamus. Nat. Neurosci. 23, 217-228. doi: 10.1038/s41593-019-0572-3

Gent, T. C., Bandarabadi, M., Herrera, C. G., and Adamantidis, A. R. (2018). Thalamic dual control of sleep and wakefulness. Nat. Neurosci. 21, 974-984. doi: 10.1038/s41593-018-0164-7

Georgescu, I. A., Popa, D., and Zagrean, L. (2020). The anatomical and functional heterogeneity of the mediodorsal thalamus. Brain Sci. 10:624. doi: 10.3390/ brainsci10090624 
Giannotti, G., Barry, S. M., Siemsen, B. M., Peters, J., and McGinty, J. F. (2018). Divergent prelimbic cortical pathways interact with BDNF to regulate cocaineseeking. J. Neurosci. 38, 8956-8966. doi: 10.1523/JNEUROSCI.1332-18.2018

Halassa, M. M., and Acsady, L. (2016). Thalamic inhibition: diverse sources, diverse scales. Trends Neuroscim 39, 680-693. doi: 10.1016/j.tins.2016.08.001

Halassa, M. M., Chen, Z., Wimmer, R. D., Brunetti, P. M., Zhao, S., Zikopoulos, B., et al. (2014). State-dependent architecture of thalamic reticular subnetworks. Cell 158, 808-821. doi: 10.1016/j.cell.2014.06.025

Halassa, M. M., Siegle, J. H., Ritt, J. T., Ting, J. T., Feng, G., and Moore, C. I. (2011). Selective optical drive of thalamic reticular nucleus generates thalamic bursts and cortical spindles. Nat. Neurosci. 14, 1118-1120. doi: 10.1038/nn.2880

Hamlin, A. S., Clemens, K. J., Choi, E. A., and McNally, G. P. (2009). Paraventricular thalamus mediates context-induced reinstatement (renewal) of extinguished reward seeking. Eur. J. Neurosci. 29, 802-812. doi: 10.1111/j.14609568.2009.06623.x

Hartikainen, K. M., Sun, L., Polvivaara, M., Brause, M., Lehtimaki, K., Haapasalo, J., et al. (2014). Immediate effects of deep brain stimulation of anterior thalamic nuclei on executive functions and emotion-attention interaction in humans. J. Clin. Exp. Neuropsychol. 36, 540-550. doi: 10.1080/13803395.2014.913554

Herkenham, M. (1979). The afferent and efferent connections of the ventromedial thalamic nucleus in the rat. J. Comp. Neurol. 183, 487-517. doi: 10.1002/cne. 901830304

Herrera, C. G., Cadavieco, M. C., Jego, S., Ponomarenko, A., Korotkova, T., and Adamantidis, A. (2016). Hypothalamic feedforward inhibition of thalamocortical network controls arousal and consciousness. Nat. Neurosci. 19, 290-298. doi: 10.1038/nn.4209

Hua, R., Wang, X., Chen, X., Wang, X., Huang, P., Li, P., et al. (2018). Calretinin neurons in the midline thalamus modulate starvation-induced arousal. Curr. Biol. 28, 3948-3959 e3944. doi: 10.1016/j.cub.2018.11.020

Huang, L., Xi, Y., Peng, Y., Yang, Y., Huang, X., Fu, Y., et al. (2019). A visual circuit related to habenula underlies the antidepressive effects of light therapy. Neuron 102, 128-142e128. doi: 10.1016/j.neuron.2019.01.037

Hubel, D. H., and Wiesel, T. N. (1962). Receptive fields, binocular interaction and functional architecture in the cat's visual cortex. J. Physiol. 160, 106-154. doi: 10.1113/jphysiol.1962.sp006837

Igelstrom, K. M., Herbison, A. E., and Hyland, B. I. (2010). Enhanced c-Fos expression in superior colliculus, paraventricular thalamus and septum during learning of cue-reward association. Neuroscience 168, 706-714. doi: 10.1016/j. neuroscience.2010.04.018

Ilyas, A., Pizarro, D., Romeo, A. K., Riley, K. O., and Pati, S. (2019). The centromedian nucleus: anatomy, physiology, and clinical implications. J. Clin. Neurosci. 63, 1-7. doi: 10.1016/j.jocn.2019.01.050

Ishibashi, M., Takano, S., Yanagida, H., Takatsuna, M., Nakajima, K., Oomura, Y., et al. (2005). Effects of orexins/hypocretins on neuronal activity in the paraventricular nucleus of the thalamus in rats in vitro. Peptides 26, 471-481. doi: 10.1016/j.peptides.2004.10.014

James, M. H., Charnley, J. L., Flynn, J. R., Smith, D. W., and Dayas, C. V. (2011a). Propensity to 'relapse' following exposure to cocaine cues is associated with the recruitment of specific thalamic and epithalamic nuclei. Neuroscience 199, 235-242. doi: 10.1016/j.neuroscience.2011.09.047

James, M. H., Charnley, J. L., Jones, E., Levi, E. M., Yeoh, J. W., Flynn, J. R., et al. (2010). Cocaine- and amphetamine-regulated transcript (CART) signaling within the paraventricular thalamus modulates cocaine-seeking behaviour. PLoS One 5:e12980. doi: 10.1371/journal.pone.0012980

James, M. H., Charnley, J. L., Levi, E. M., Jones, E., Yeoh, J. W., Smith, D. W., et al. (2011b). Orexin-1 receptor signalling within the ventral tegmental area, but not the paraventricular thalamus, is critical to regulating cue-induced reinstatement of cocaine-seeking. Int. J. Neuropsychopharmacol. 14, 684-690. doi: $10.1017 /$ S1461145711000423

Jeon, D., Kim, S., Chetana, M., Jo, D., Ruley, H. E., Lin, S. Y., et al. (2010). Observational fear learning involves affective pain system and Cav1.2 $\mathrm{Ca}^{2+}$ channels in ACC. Nat. Neurosci. 13, 482-488. doi: 10.1038/nn.2504

Jurik, A., Auffenberg, E., Klein, S., Deussing, J. M., Schmid, R. M., Wotjak, C. T., et al. (2015). Roles of prefrontal cortex and paraventricular thalamus in affective and mechanical components of visceral nociception. Pain 156, 2479-2491. doi: 10.1097/j.pain.0000000000000318
Kamikawa, K., Noda, H., Miyagawa, S., Mogami, H., and Jinnai, D. (1967). Nonspecific projection system of the thalamus and bilateral motor control of subcortical nuclei. Confin. Neurol. 29, 112-116. doi: 10.1159/000103688

Kapur, S. (2003). Psychosis as a state of aberrant salience: a framework linking biology, phenomenology, and pharmacology in schizophrenia. Am. J. Psychiatry 160, 13-23. doi: 10.1176/appi.ajp.160.1.13

Kato, S., Fukabori, R., Nishizawa, K., Okada, K., Yoshioka, N., Sugawara, M., et al. (2018). Action selection and flexible switching controlled by the intralaminar thalamic neurons. Cell Rep. 22, 2370-2382. doi: 10.1016/j.celrep.2018.02.016

Keyes, P. C., Adams, E. L., Chen, Z., Bi, L., Nachtrab, G., Wang, V. J., et al. (2020). Orchestrating opiate-associated memories in thalamic circuits. Neuron 107, 1113-1123e1114. doi: 10.1016/j.neuron.2020.06.028

Kim, B. H., Shin, Y. B., Kyeong, S., Lee, S. K., and Kim, J. J. (2018). Disrupted salience processing involved in motivational deficits for real-life activities in patients with schizophrenia. Schizophr. Res. 197, 407-413. doi: 10.1016/j.schres. 2018.01.019

Kim, D., Park, D., Choi, S., Lee, S., Sun, M., Kim, C., et al. (2003). Thalamic control of visceral nociception mediated by T-type Ca2+ channels. Science 302, 117-119. doi: 10.1126/science. 1088886

Kirouac, G. J. (2015). Placing the paraventricular nucleus of the thalamus within the brain circuits that control behavior. Neurosci. Biobehav. Rev. 56, 315-329. doi: 10.1016/j.neubiorev.2015.08.005

Kolaj, M., Zhang, L., Hermes, M. L., and Renaud, L. P. (2014). Intrinsic properties and neuropharmacology of midline paraventricular thalamic nucleus neurons. Front. Behav. Neurosci. 8:132. doi: 10.3389/fnbeh.2014.00132

Konick, L. C., and Friedman, L. (2001). Meta-analysis of thalamic size in schizophrenia. Biol. Psychiatry 49, 28-38. doi: 10.1016/s0006-3223(00)00974-4

Koob, G. F., and Volkow, N. D. (2016). Neurobiology of addiction: a neurocircuitry analysis. Lancet Psychiatry 3, 760-773. doi: 10.1016/S2215-0366(16)00104-8

Krol, A., Wimmer, R. D., Halassa, M. M., and Feng, G. (2018). Thalamic reticular dysfunction as a circuit endophenotype in neurodevelopmental disorders. Neuron 98, 282-295. doi: 10.1016/j.neuron.2018.03.021

Krout, K. E., Belzer, R. E., and Loewy, A. D. (2002). Brainstem projections to midline and intralaminar thalamic nuclei of the rat. J. Comp. Neurol. 448, 53-101. doi: 10.1002/cne.10236

Kuhn, B. N., Klumpner, M. S., Covelo, I. R., Campus, P., and Flagel, S. B. (2018). Transient inactivation of the paraventricular nucleus of the thalamus enhances cue-induced reinstatement in goal-trackers, but not sign-trackers. Psychopharmacology (Berl.) 235, 999-1014. doi: 10.1007/s00213-017-4816-1

Kumar, V. J., van Oort, E., Scheffler, K., Beckmann, C. F., and Grodd, W. (2017). Functional anatomy of the human thalamus at rest. Neuroimage 147, 678-691. doi: 10.1016/j.neuroimage.2016.12.071

Kummer, K. K., Mitric, M., Kalpachidou, T., and Kress, M. (2020). The medial prefrontal cortex as a central hub for mental comorbidities associated with chronic pain. Int. J. Mol. Sci. 21:3440. doi: 10.3390/ijms21103440

Kuramoto, E., Ohno, S., Furuta, T., Unzai, T., Tanaka, Y. R., Hioki, H., et al. (2015). Ventral medial nucleus neurons send thalamocortical afferents more widely and more preferentially to layer 1 than neurons of the ventral anterior-ventral lateral nuclear complex in the rat. Cereb. Cortex 25, 221-235. doi: 10.1093/cercor/ bht216

Kuramoto, E., Pan, S., Furuta, T., Tanaka, Y. R., Iwai, H., Yamanaka, A., et al. (2017). Individual mediodorsal thalamic neurons project to multiple areas of the rat prefrontal cortex: a single neuron-tracing study using virus vectors. J. Comp. Neurol. 525, 166-185. doi: 10.1002/cne.24054

Kuroda, M., Yokofujita, J., Oda, S., and Price, J. L. (2004). Synaptic relationships between axon terminals from the mediodorsal thalamic nucleus and gammaaminobutyric acidergic cortical cells in the prelimbic cortex of the rat. J. Comp. Neurol. 477, 220-234. doi: 10.1002/cne.20249

Lanius, R. A., Williamson, P. C., Densmore, M., Boksman, K., Gupta, M. A., Neufeld, R. W., et al. (2001). Neural correlates of traumatic memories in posttraumatic stress disorder: a functional MRI investigation. Am. J. Psychiatry 158, 1920-1922. doi: 10.1176/appi.ajp.158.11.1920

Leaver, A. M., Espinoza, R., Pirnia, T., Joshi, S. H., Woods, R. P., and Narr, K. L. (2016). Modulation of intrinsic brain activity by electroconvulsive therapy in major depression. Biol. Psychiatry Cogn. Neurosci. Neuroimaging 1, 77-86. doi: 10.1016/j.bpsc.2015.09.001 
Lee, J. H., Latchoumane, C. V., Park, J., Kim, J., Jeong, J., Lee, K. H., et al. (2019). The rostroventral part of the thalamic reticular nucleus modulates fear extinction. Nat. Commun. 10:4637. doi: 10.1038/s41467-019-12496-9

Lee, S., Ahmed, T., Lee, S., Kim, H., Choi, S., Kim, D. S., et al. (2011). Bidirectional modulation of fear extinction by mediodorsal thalamic firing in mice. Nat. Neurosci. 15, 308-314. doi: 10.1038/nn.2999

Leszczynski, M., and Staudigl, T. (2016). Memory-guided attention in the anterior thalamus. Neurosci. Biobehav. Rev. 66, 163-165. doi: 10.1016/j.neubiorev.2016. 04.015

Lewis, L. D., Voigts, J., Flores, F. J., Schmitt, L. I., Wilson, M. A., Halassa, M. M., et al. (2015). Thalamic reticular nucleus induces fast and local modulation of arousal state. Elife 4:e08760. doi: 10.7554/eLife.08760

Li, S., and Kirouac, G. J. (2012). Sources of inputs to the anterior and posterior aspects of the paraventricular nucleus of the thalamus. Brain Struct. Funct. 217, 257-273. doi: 10.1007/s00429-011-0360-7

Li, X., Rubio, F. J., Zeric, T., Bossert, J. M., Kambhampati, S., Cates, H. M., et al. (2015). Incubation of methamphetamine craving is associated with selective increases in expression of Bdnf and trkb, glutamate receptors, and epigenetic enzymes in cue-activated fos-expressing dorsal striatal neurons. J. Neurosci. 35, 8232-8244. doi: 10.1523/JNEUROSCI.1022-15.2015

Li, X., Witonsky, K. R., Lofaro, O. M., Surjono, F., Zhang, J., Bossert, J. M., et al. (2018). Role of anterior intralaminar nuclei of thalamus projections to dorsomedial striatum in incubation of methamphetamine craving. J. Neurosci. 38, 2270-2282. doi: 10.1523/JNEUROSCI.2873-17.2018

Li, X. B., Inoue, T., Nakagawa, S., and Koyama, T. (2004). Effect of mediodorsal thalamic nucleus lesion on contextual fear conditioning in rats. Brain Res. 1008, 261-272. doi: 10.1016/j.brainres.2004.02.038

Li, Y., Wang, H., Qi, K., Chen, X., Li, S., Sui, N., et al. (2011). Orexins in the midline thalamus are involved in the expression of conditioned place aversion to morphine withdrawal. Physiol. Behav. 102, 42-50. doi: 10.1016/j.physbeh. 2010.10.006

Liang, H. Y., Chen, Z. J., Xiao, H., Lin, Y. H., Hu, Y. Y., Chang, L., et al. (2020a). nNOS-expressing neurons in the vmPFC transform pPVT-derived chronic pain signals into anxiety behaviors. Nat. Commun. 11:2501. doi: 10.1038/s41467020-16198-5

Liang, S. H., Zhao, W. J., Yin, J. B., Chen, Y. B., Li, J. N., Feng, B., et al. (2020b). A neural circuit from thalamic paraventricular nucleus to central amygdala for the facilitation of neuropathic pain. J. Neurosci. 40, 7837-7854. doi: 10.1523/ JNEUROSCI.2487-19.2020

Livneh, Y., Ramesh, R. N., Burgess, C. R., Levandowski, K. M., Madara, J. C., Fenselau, H., et al. (2017). Homeostatic circuits selectively gate food cue responses in insular cortex. Nature 546, 611-616. doi: 10.1038/nature22375

Lu, L., Grimm, J. W., Hope, B. T., and Shaham, Y. (2004). Incubation of cocaine craving after withdrawal: a review of preclinical data. Neuropharmacology 47(Suppl. 1), 214-226. doi: 10.1016/j.neuropharm.2004.06.027

Mansour, A., Lewis, M. E., Khachaturian, H., Akil, H., and Watson, S. J. (1986). Pharmacological and anatomical evidence of selective mu, delta, and kappa opioid receptor binding in rat brain. Brain Res. 399, 69-79. doi: 10.1016/00068993(86)90601-3

Massimini, M., Ferrarelli, F., Huber, R., Esser, S. K., Singh, H., and Tononi, G. (2005). Breakdown of cortical effective connectivity during sleep. Science 309, 2228-2232. doi: 10.1126/science.1117256

Matsumoto, N., Minamimoto, T., Graybiel, A. M., and Kimura, M. (2001). Neurons in the thalamic CM-Pf complex supply striatal neurons with information about behaviorally significant sensory events. J. Neurophysiol. 85, 960-976. doi: 10. $1152 /$ in.2001.85.2.960

Matyas, F., Komlosi, G., Babiczky, A., Kocsis, K., Bartho, P., Barsy, B., et al. (2018). A highly collateralized thalamic cell type with arousal-predicting activity serves as a key hub for graded state transitions in the forebrain. Nat. Neurosci. 21, 1551-1562. doi: 10.1038/s41593-018-0251-9

Matyas, F., Lee, J., Shin, H. S., and Acsady, L. (2014). The fear circuit of the mouse forebrain: connections between the mediodorsal thalamus, frontal cortices and basolateral amygdala. Eur. J. Neurosci. 39, 1810-1823. doi: 10.1111/ejn.12610

Matzeu, A., Kallupi, M., George, O., Schweitzer, P., and Martin-Fardon, R. (2018). Dynorphin counteracts orexin in the paraventricular nucleus of the thalamus: cellular and behavioral evidence. Neuropsychopharmacology 43, 1010-1020. doi: $10.1038 / \mathrm{npp} .2017 .250$
Matzeu, A., Kerr, T. M., Weiss, F., and Martin-Fardon, R. (2016). OrexinA/Hypocretin-1 mediates cocaine-seeking behavior in the posterior paraventricular nucleus of the thalamus via Orexin/Hypocretin receptor-2. J. Pharmacol. Exp. Ther. 359, 273-279. doi: 10.1124/jpet.116.235945

Matzeu, A., Zamora-Martinez, E. R., and Martin-Fardon, R. (2014). The paraventricular nucleus of the thalamus is recruited by both natural rewards and drugs of abuse: recent evidence of a pivotal role for orexin/hypocretin signaling in this thalamic nucleus in drug-seeking behavior. Front. Behav. Neurosci. 8:117. doi: 10.3389/fnbeh.2014.00117

McAlonan, K., Cavanaugh, J., and Wurtz, R. H. (2008). Guarding the gateway to cortex with attention in visual thalamus. Nature 456, 391-394. doi: 10.1038/ nature 07382

McGinty, J. F., and Otis, J. M. (2020). Heterogeneity in the paraventricular thalamus: the traffic light of motivated behaviors. Front. Behav. Neurosci. 14:590528. doi: 10.3389/fnbeh.2020.590528

Meda, K. S., Patel, T., Braz, J. M., Malik, R., Turner, M. L., Seifikar, H., et al. (2019). Microcircuit mechanisms through which mediodorsal thalamic input to anterior cingulate cortex exacerbates pain-related aversion. Neuron 102, 944-959 e943. doi: 10.1016/j.neuron.2019.03.042

Meffre, J., Sicre, M., Diarra, M., Marchessaux, F., Paleressompoulle, D., and Ambroggi, F. (2019). Orexin in the posterior paraventricular thalamus mediates hunger-related signals in the nucleus accumbens core. Curr. Biol. 29, 3298-3306 e3294. doi: 10.1016/j.cub.2019.07.069

Menon, V. (2011). Large-scale brain networks and psychopathology: a unifying triple network model. Trends Cogn. Sci. 15, 483-506. doi: 10.1016/j.tics.2011. 08.003

Millan, E. Z., Ong, Z., and McNally, G. P. (2017). Paraventricular thalamus: gateway to feeding, appetitive motivation, and drug addiction. Prog. Brain Res. 235, 113-137. doi: 10.1016/bs.pbr.2017.07.006

Miller, O. H., Bruns, A., Ben Ammar, I., Mueggler, T., and Hall, B. J. (2017). Synaptic regulation of a thalamocortical circuit controls depression-related behavior. Cell Rep. 20, 1867-1880. doi: 10.1016/j.celrep.2017.08.002

Minamimoto, T., and Kimura, M. (2002). Participation of the thalamic CM-Pf complex in attentional orienting. J. Neurophysiol. 87, 3090-3101. doi: 10.1152/ jn.2002.87.6.3090

Mitchell, A. S. (2015). The mediodorsal thalamus as a higher order thalamic relay nucleus important for learning and decision-making. Neurosci. Biobehav. Rev. 54, 76-88. doi: 10.1016/j.neubiorev.2015.03.001

Munkhzaya, U., Chinzorig, C., Matsumoto, J., Nishimaru, H., Ono, T., and Nishijo, H. (2020). Rat paraventricular neurons encode predictive and incentive information of reward cues. Front. Behav. Neurosci. 14:565002. doi: 10.3389/ fnbeh.2020.565002

Nakajima, M., and Halassa, M. M. (2017). Thalamic control of functional cortical connectivity. Curr. Opin. Neurobiol. 44, 127-131. doi: 10.1016/j.conb.2017. 04.001

Nakajima, M., Schmitt, L. I., and Halassa, M. M. (2019). Prefrontal cortex regulates sensory filtering through a basal ganglia-to-thalamus pathway. Neuron 103, 445-458e410. doi: 10.1016/j.neuron.2019.05.026

Neumann, P. A., Wang, Y., Yan, Y., Wang, Y., Ishikawa, M., Cui, R., et al. (2016). Cocaine-induced synaptic alterations in thalamus to nucleus accumbens projection. Neuropsychopharmacology 41, 2399-2410. doi: 10.1038/npp. 2016.52

Ni, K. M., Hou, X. J., Yang, C. H., Dong, P., Li, Y., Zhang, Y., et al. (2016). Selectively driving cholinergic fibers optically in the thalamic reticular nucleus promotes sleep. Elife 5:e10382. doi: 10.7554/eLife.10382

Novo Navarro, P., Landin-Romero, R., Guardiola-Wanden-Berghe, R., MorenoAlcazar, A., Valiente-Gomez, A., Lupo, W., et al. (2018). 25 years of eye movement desensitization and reprocessing (EMDR): the EMDR therapy protocol, hypotheses of its mechanism of action and a systematic review of its efficacy in the treatment of post-traumatic stress disorder. Rev. Psiquiatr. Salud Ment. 11, 101-114. doi: 10.1016/j.rpsm.2015.12.002

Ong, Z. Y., Liu, J. J., Pang, Z. P., and Grill, H. J. (2017). Paraventricular thalamic control of food intake and reward: role of glucagon-like peptide-1 receptor signaling. Neuropsychopharmacology 42, 2387-2397. doi: 10.1038/npp.20 17.150

Padilla-Coreano, N., Do-Monte, F. H., and Quirk, G. J. (2012). A timedependent role of midline thalamic nuclei in the retrieval of fear 
memory. Neuropharmacology 62, 457-463. doi: 10.1016/j.neuropharm.2011. 08.037

Pandey, S., Badve, P. S., Curtis, G. R., Leibowitz, S. F., and Barson, J. R. (2019). Neurotensin in the posterior thalamic paraventricular nucleus: inhibitor of pharmacologically relevant ethanol drinking. Addict. Biol. 24, 3-16. doi: 10. 1111/adb. 12546

Pannekoek, J. N., van der Werff, S. J., Meens, P. H., van den Bulk, B. G., Jolles, D. D., Veer, I. M., et al. (2014). Aberrant resting-state functional connectivity in limbic and salience networks in treatment-naive clinically depressed adolescents. J. Child Psychol. Psychiatry 55, 1317-1327. doi: 10.1111/jcpp.12266

Parnaudeau, S., Bolkan, S. S., and Kellendonk, C. (2018). The mediodorsal thalamus: an essential partner of the prefrontal cortex for cognition. Biol. Psychiatry 83, 648-656. doi: 10.1016/j.biopsych.2017.11.008

Parnaudeau, S., O’Neill, P. K., Bolkan, S. S., Ward, R. D., Abbas, A. I., Roth, B. L., et al. (2013). Inhibition of mediodorsal thalamus disrupts thalamofrontal connectivity and cognition. Neuron 77, 1151-1162. doi: 10.1016/j.neuron.2013. 01.038

Paydar, A., Lee, B., Gangadharan, G., Lee, S., Hwang, E. M., and Shin, H. S. (2014). Extrasynaptic GABAA receptors in mediodorsal thalamic nucleus modulate fear extinction learning. Mol. Brain 7:39. doi: 10.1186/1756-6606-7-39

Penzo, M. A., Robert, V., Tucciarone, J., De Bundel, D., Wang, M., Van Aelst, L., et al. (2015). The paraventricular thalamus controls a central amygdala fear circuit. Nature 519, 455-459. doi: 10.1038/nature 13978

Pergola, G., Danet, L., Pitel, A. L., Carlesimo, G. A., Segobin, S., Pariente, J., et al. (2018). The regulatory role of the human mediodorsal thalamus. Trends Cogn. Sci. 22, 1011-1025. doi: 10.1016/j.tics.2018.08.006

Pergola, G., Selvaggi, P., Trizio, S., Bertolino, A., and Blasi, G. (2015). The role of the thalamus in schizophrenia from a neuroimaging perspective. Neurosci. Biobehav. Rev. 54, 57-75. doi: 10.1016/j.neubiorev.2015.01.013

Peters, S. K., Dunlop, K., and Downar, J. (2016). Cortico-Striatal-thalamic loop circuits of the salience network: a central pathway in psychiatric disease and treatment. Front. Syst. Neurosci. 10:104. doi: 10.3389/fnsys.2016.00104

Phillips, J. M., Kambi, N. A., and Saalmann, Y. B. (2016). A subcortical pathway for rapid, goal-driven, attentional filtering. Trends Neurosci. 39, 49-51. doi: 10.1016/j.tins.2015.12.003

Pickens, C. L., Airavaara, M., Theberge, F., Fanous, S., Hope, B. T., and Shaham, Y. (2011). Neurobiology of the incubation of drug craving. Trends Neurosci. 34, 411-420. doi: 10.1016/j.tins.2011.06.001

Pinault, D., and Deschenes, M. (1998). Anatomical evidence for a mechanism of lateral inhibition in the rat thalamus. Eur. J. Neurosci. 10, 3462-3469. doi: 10.1046/j.1460-9568.1998.00362.x

Puglisi-Allegra, S., and Ventura, R. (2012). Prefrontal/accumbal catecholamine system processes emotionally driven attribution of motivational salience. Rev. Neurosci. 23, 509-526. doi: 10.1515/revneuro-2012-0076

Ramanathan, K. R., and Maren, S. (2019). Nucleus reuniens mediates the extinction of contextual fear conditioning. Behav. Brain Res. 374:112114. doi: 10.1016/j. bbr.2019.112114

Ren, S., Wang, Y., Yue, F., Cheng, X., Dang, R., Qiao, Q., et al. (2018). The paraventricular thalamus is a critical thalamic area for wakefulness. Science 362, 429-434. doi: 10.1126/science.aat2512

Rikhye, R. V., Gilra, A., and Halassa, M. M. (2018). Thalamic regulation of switching between cortical representations enables cognitive flexibility. Nat. Neurosci. 21, 1753-1763. doi: 10.1038/s41593-018-0269-z

Robinson, D. L., and Petersen, S. E. (1992). The pulvinar and visual salience. Trends Neurosci. 15, 127-132. doi: 10.1016/0166-2236(92)90354-b

Roland, P. (1992). Cortical representation of pain. Trends Neurosci. 15, 3-5. doi: 10.1016/0166-2236(92)90337-8

Rossi, L. M., Reverte, I., Ragozzino, D., Badiani, A., Venniro, M., and Caprioli, D. (2020). Role of nucleus accumbens core but not shell in incubation of methamphetamine craving after voluntary abstinence. Neuropsychopharmacology 45, 256-265. doi: 10.1038/s41386-019-0479-4

Rotaru, D. C., Barrionuevo, G., and Sesack, S. R. (2005). Mediodorsal thalamic afferents to layer III of the rat prefrontal cortex: synaptic relationships to subclasses of interneurons. J. Comp. Neurol 490, 220-238. doi: 10.1002/cne. 20661

Rubio-Garrido, P., Perez-de-Manzo, F., Porrero, C., Galazo, M. J., and Clasca, F. (2009). Thalamic input to distal apical dendrites in neocortical layer 1 is massive and highly convergent. Cereb. Cortex 19, 2380-2395. doi: 10.1093/ cercor/bhn259

Russchen, F. T., Amaral, D. G., and Price, J. L. (1987). The afferent input to the magnocellular division of the mediodorsal thalamic nucleus in the monkey, Macaca fascicularis. J. Comp. Neurol. 256, 175-210. doi: 10.1002/cne.902560202

Rzepa, E., and McCabe, C. (2016). Decreased anticipated pleasure correlates with increased salience network resting state functional connectivity in adolescents with depressive symptomatology. J. Psychiatr Res. 82, 40-47. doi: 10.1016/j. jpsychires.2016.07.013

Sakai, K. (2008). Task set and prefrontal cortex. Annu. Rev. Neurosci. 31, 219-245. doi: 10.1146/annurev.neuro.31.060407.125642

Salay, L. D., Ishiko, N., and Huberman, A. D. (2018). A midline thalamic circuit determines reactions to visual threat. Nature 557, 183-189. doi: 10.1038/ s41586-018-0078-2

Salomons, T. V., Dunlop, K., Kennedy, S. H., Flint, A., Geraci, J., Giacobbe, P., et al. (2014). Resting-state cortico-thalamic-striatal connectivity predicts response to dorsomedial prefrontal rTMS in major depressive disorder. Neuropsychopharmacology 39, 488-498. doi: 10.1038/npp.2013.222

Saund, J., Dautan, D., Rostron, C., Urcelay, G. P., and Gerdjikov, T. V. (2017). Thalamic inputs to dorsomedial striatum are involved in inhibitory control: evidence from the five-choice serial reaction time task in rats. Psychopharmacology (Berl.) 234, 2399-2407. doi: 10.1007/s00213-017-4627-4

Schmahmann, J. D. (2003). Vascular syndromes of the thalamus. Stroke 34, 2264 2278. doi: 10.1161/01.STR.0000087786.38997.9E

Schmitt, L. I., Wimmer, R. D., Nakajima, M., Happ, M., Mofakham, S., and Halassa, M. M. (2017). Thalamic amplification of cortical connectivity sustains attentional control. Nature 545, 219-223. doi: 10.1038/nature22073

Seeley, W. W., Menon, V., Schatzberg, A. F., Keller, J., Glover, G. H., Kenna, H., et al. (2007). Dissociable intrinsic connectivity networks for salience processing and executive control. J. Neurosci. 27, 2349-2356. doi: 10.1523/JNEUROSCI. 5587-06.2007

Sharp, F. R., Tomitaka, M., Bernaudin, M., and Tomitaka, S. (2001). Psychosis: pathological activation of limbic thalamocortical circuits by psychomimetics and schizophrenia? Trends Neurosci. 24, 330-334. doi: 10.1016/s0166-2236(00) 01817-8

Sherman, S. M. (2001). Tonic and burst firing: dual modes of thalamocortical relay. Trends Neurosci. 24, 122-126. doi: 10.1016/s0166-2236(00)01714-8

Sherman, S. M. (2007). The thalamus is more than just a relay. Curr. Opin. Neurobiol. 17, 417-422. doi: 10.1016/j.conb.2007.07.003

Shin, C. B., Serchia, M. M., Shahin, J. R., Ruppert-Majer, M. A., Kippin, T. E., and Szumlinski, K. K. (2016). Incubation of cocaine-craving relates to glutamate over-flow within ventromedial prefrontal cortex. Neuropharmacology 102, $103-$ 110. doi: 10.1016/j.neuropharm.2015.10.038

Steullet, P., Cabungcal, J. H., Bukhari, S. A., Ardelt, M. I., Pantazopoulos, H., Hamati, F., et al. (2018). The thalamic reticular nucleus in schizophrenia and bipolar disorder: role of parvalbumin-expressing neuron networks and oxidative stress. Mol. Psychiatry 23, 2057-2065. doi: 10.1038/mp.2017.230

Stratford, T. R., and Wirtshafter, D. (2013). Injections of muscimol into the paraventricular thalamic nucleus, but not mediodorsal thalamic nuclei, induce feeding in rats. Brain Res. 1490, 128-133. doi: 10.1016/j.brainres.2012.10.043

Suarez-Jimenez, B., Albajes-Eizagirre, A., Lazarov, A., Zhu, X., Harrison, B. J., Radua, J., et al. (2020). Neural signatures of conditioning, extinction learning, and extinction recall in posttraumatic stress disorder: a meta-analysis of functional magnetic resonance imaging studies. Psychol. Med. 50, 1442-1451. doi: 10.1017/S0033291719001387

Sun, L., Perakyla, J., Polvivaara, M., Ohman, J., Peltola, J., Lehtimaki, K., et al. (2015). Human anterior thalamic nuclei are involved in emotion-attention interaction. Neuropsychologia 78, 88-94. doi: 10.1016/j.neuropsychologia.2015. 10.001

Takahashi, S., Glatt, S. J., Uchiyama, M., Faraone, S. V., and Tsuang, M. T. (2015). Meta-analysis of data from the psychiatric genomics consortium and additional samples supports association of CACNA1C with risk for schizophrenia. Schizophr. Res. 168, 429-433. doi: 10.1016/j.schres.2015.07.033

Uddin, L. Q. (2015). Salience processing and insular cortical function and dysfunction. Nat. Rev. Neurosci. 16, 55-61. doi: 10.1038/nrn3857

Van der Werf, Y. D., Witter, M. P., and Groenewegen, H. J. (2002). The intralaminar and midline nuclei of the thalamus. Anatomical and functional evidence for 
participation in processes of arousal and awareness. Brain Res. Brain Res. Rev. 39, 107-140. doi: 10.1016/s0165-0173(02)00181-9

van Os, J., and Kapur, S. (2009). Schizophrenia. Lancet 374, 635-645. doi: 10.1016/ S0140-6736(09)60995-8

Vertes, R. P., Linley, S. B., and Hoover, W. B. (2015). Limbic circuitry of the midline thalamus. Neurosci. Biobehav. Rev. 54, 89-107. doi: 10.1016/j.neubiorev.2015. 01.014

Volz, H., Gaser, C., and Sauer, H. (2000). Supporting evidence for the model of cognitive dysmetria in schizophrenia-a structural magnetic resonance imaging study using deformation-based morphometry. Schizophr. Res. 46, 45-56. doi: 10.1016/s0920-9964(99)00236-4

Wang, L., Hermens, D. F., Hickie, I. B., and Lagopoulos, J. (2012). A systematic review of resting-state functional-MRI studies in major depression. J. Affect. Disord. 142, 6-12. doi: 10.1016/j.jad.2012.04.013

Watarai, A., Tsutaki, S., Nishimori, K., Okuyama, T., Mogi, K., and Kikusui, T. (2020). The blockade of oxytocin receptors in the paraventricular thalamus reduces maternal crouching behavior over pups in lactating mice. Neurosci. Lett. 720:134761. doi: 10.1016/j.neulet.2020.134761

Watis, L., Chen, S. H., Chua, H. C., Chong, S. A., and Sim, K. (2008). Glutamatergic abnormalities of the thalamus in schizophrenia: a systematic review. J. Neural. Transm. (Vienna) 115, 493-511. doi: 10.1007/s00702-007-0859-5

Wimmer, R. D., Schmitt, L. I., Davidson, T. J., Nakajima, M., Deisseroth, K., and Halassa, M. M. (2015). Thalamic control of sensory selection in divided attention. Nature 526, 705-709. doi: 10.1038/nature15398

Wolff, M., and Vann, S. D. (2019). The cognitive thalamus as a gateway to mental representations. J. Neurosci. 39, 3-14. doi: 10.1523/JNEUROSCI.0479-18.2018

Woodward, N. D., Karbasforoushan, H., and Heckers, S. (2012). Thalamocortical dysconnectivity in schizophrenia. Am. J. Psychiatry 169, 1092-1099. doi: 10. 1176/appi.ajp.2012.12010056

Wright, N. F., Vann, S. D., Aggleton, J. P., and Nelson, A. J. (2015). A critical role for the anterior thalamus in directing attention to task-relevant stimuli. J. Neurosci. 35, 5480-5488. doi: 10.1523/JNEUROSCI.4945-14.2015

Yamamuro, K., Bicks, L. K., Leventhal, M. B., Kato, D., Im, S., Flanigan, M. E., et al. (2020). A prefrontal-paraventricular thalamus circuit requires juvenile social experience to regulate adult sociability in mice. Nat. Neurosci. 23, 1240-1252. doi: 10.1038/s41593-020-0695-6

Yamanaka, K., Hori, Y., Minamimoto, T., Yamada, H., Matsumoto, N., Enomoto, K., et al. (2018). Roles of centromedian parafascicular nuclei of thalamus and cholinergic interneurons in the dorsal striatum in associative learning of environmental events. J. Neural. Transm. (Vienna) 125, 501-513. doi: 10.1007/ s00702-017-1713-z

Yan, X., Brown, A. D., Lazar, M., Cressman, V. L., Henn-Haase, C., Neylan, T. C., et al. (2013). Spontaneous brain activity in combat related PTSD. Neurosci. Lett. 547, 1-5. doi: 10.1016/j.neulet.2013.04.032

Yen, C. T., and Lu, P. L. (2013). Thalamus and pain. Acta Anaesthesiol. Taiwan 51, 73-80. doi: 10.1016/j.aat.2013.06.011

Yeo, B. T., Krienen, F. M., Sepulcre, J., Sabuncu, M. R., Lashkari, D., Hollinshead, M., et al. (2011). The organization of the human cerebral cortex estimated by intrinsic functional connectivity. J. Neurophysiol. 106, 1125-1165. doi: 10.1152/ jn.00338.2011

Yeoh, J. W., James, M. H., Graham, B. A., and Dayas, C. V. (2014). Electrophysiological characteristics of paraventricular thalamic (PVT) neurons in response to cocaine and cocaine- and amphetamine-regulated transcript (CART). Front. Behav. Neurosci. 8:280. doi: 10.3389/fnbeh.2014.00280

Young, C. D., and Deutch, A. Y. (1998). The effects of thalamic paraventricular nucleus lesions on cocaine-induced locomotor activity and sensitization. Pharmacol. Biochem. Behav. 60, 753-758. doi: 10.1016/s0091-3057(98)00051-3

Yuan, X. S., Wei, H. H., Xu, W., Wang, L., Qu, W. M., Li, R. X., et al. (2018). Whole-brain monosynaptic afferent projections to the cholecystokinin neurons of the suprachiasmatic nucleus. Front. Neurosci. 12:807. doi: 10.3389/fnins. 2018.00807

Yuen, G. S., Gunning-Dixon, F. M., Hoptman, M. J., AbdelMalak, B., McGovern, A. R., Seirup, J. K., et al. (2014). The salience network in the apathy of late-life depression. Int. J. Geriatr. Psychiatry 29, 1116-1124. doi: 10.1002/gps.4171

Zhang, X., and van den Pol, A. N. (2017). Rapid binge-like eating and body weight gain driven by zona incerta GABA neuron activation. Science 356, 853-859. doi: 10.1126/science.aam7100

Zhang, Y., Fu, B., Liu, C., Yu, S., Luo, T., Zhang, L., et al. (2019). Activation of noradrenergic terminals in the reticular thalamus delays arousal from propofol anesthesia in mice. FASEB J. 33, 7252-7260. doi: 10.1096/fj.201802164RR

Zheng, C., Huang, Y., Bo, B., Wei, L., Liang, Z., and Wang, Z. (2020). Projection from the anterior cingulate cortex to the lateral part of mediodorsal thalamus modulates vicarious freezing behavior. Neurosci. Bull. 36, 217-229. doi: 10. 1007/s12264-019-00427-z

Zhou, K., and Zhu, Y. (2019). The paraventricular thalamic nucleus: a key hub of neural circuits underlying drug addiction. Pharmacol. Res. 142, 70-76. doi: 10.1016/j.phrs.2019.02.014

Zhou, T., Zhu, H., Fan, Z., Wang, F., Chen, Y., Liang, H., et al. (2017). History of winning remodels thalamo-PFC circuit to reinforce social dominance. Science 357, 162-168. doi: 10.1126/science.aak9726

Zhou, W., Jin, Y., Meng, Q., Zhu, X., Bai, T., Tian, Y., et al. (2019). A neural circuit for comorbid depressive symptoms in chronic pain. Nat. Neurosci. 22, 1649-1658. doi: 10.1038/s41593-019-0468-2

Zhu, Y., Nachtrab, G., Keyes, P. C., Allen, W. E., Luo, L., and Chen, X. (2018). Dynamic salience processing in paraventricular thalamus gates associative learning. Science 362, 423-429. doi: 10.1126/science.aat0481

Zhu, Y., Wienecke, C. F., Nachtrab, G., and Chen, X. (2016). A thalamic input to the nucleus accumbens mediates opiate dependence. Nature 530, 219-222. doi: $10.1038 /$ nature 16954

Zikopoulos, B., and Barbas, H. (2012). Pathways for emotions and attention converge on the thalamic reticular nucleus in primates. J. Neurosci. 32, 5338 5350. doi: 10.1523/JNEUROSCI.4793-11.2012

Conflict of Interest: The authors declare that the research was conducted in the absence of any commercial or financial relationships that could be construed as a potential conflict of interest.

Copyright (c) 2021 Zhou, Zhu, Hou, Chen, Chen, Yang and Zhu. This is an openaccess article distributed under the terms of the Creative Commons Attribution License (CC BY). The use, distribution or reproduction in other forums is permitted, provided the original author(s) and the copyright owner(s) are credited and that the original publication in this journal is cited, in accordance with accepted academic practice. No use, distribution or reproduction is permitted which does not comply with these terms. 